Objectives: A systematic literature review (SLR) was conducted to review and summarise economic consequences of NMS from a biologic originator to its biosimilar.

Methods: English publications reporting HRU or costs associated with biosimilar NMS were searched in PubMed and Embase over the past 10 years, and from selected scientific conferences over the past 3 years, along with grey literature (e. g., organisational reports). Search strings for keywords (e.g. biosimilar, HRU, cost, switch etc.) were combined using Boolean operators for all relevant agents with an approved biosimilar (e.g., tumor-necrosis factor inhibitors, erythropoiesisstimulating agents, insulin, hormone therapies).

Results: A total of 244 publications were retrieved for review, where 122 were identified from the database search, 117 from conference abstracts and 5 from grey literature. Of these publications, 23 reported costs or HRU associated with biosimilar NMS, including 10 center-based cohort studies (all except one were single arm), 10 budget impact models/simulation studies, 2 national registry studies, and 1 policy review. Only three studies reported real-world HRU: a single-centre, two-cohort study found that switching to biosimilars was associated with higher inpatient readmission rate $(80 \%$ vs $5 \%, \mathrm{p}<0.001)$, surgery rate $(29 \%$ vs. $0 \%$, $\mathrm{p}=0.02)$, and steroid use ( $60 \%$ vs. $8 \%, p<0.001)$; a single-centre, single-arm study reported extra visit/phone consultation with a provider among patients experiencing injection-site pain; a national registry-based study found that comparing 6 months before vs. after NMS, post-NMS had increased outpatient visit days (5.7 vs $5.4, p<0.001)$ and increased rates in $6 / 16$ service categories. Among the other 20 studies, most of them focused on potential cost savings with approximately half considering drug cost only. Estimation/simulation in cost savings varied substantially due to heterogeneity in study design and assumptions (e.g. disease areas, drug price discount rates, cost components, population size, study period etc.). Among these, discontinuing/switching or switching back to the originator was reported in four studies (rate range: $6 \%-29 \%$ ) and biosimilar dosing increase $(35 \%)$ was reported in one study. A policy review study pointed out that biologic rebates (commonly at $50 \%$ ) should be taken into account in the context of NMS.

Conclusions: Few real-world studies reported economic consequences of biosimilar NMS and found increased HRU in patients with biosimilar NMS. Studies of cost estimation have been largely limited to drug prices. Comprehensive evaluation on the economic impact of NMS should incorporate all important elements of economic outcomes such as drug price, biologic rebates, HRU, NMS program setup, administration, and monitoring costs.

Acknowledgements: Medical writing support was provided by Jessie Wang of Analysis Group; this support was funded by AbbVie.

Disclosure of Interest: Y. Liu Consultant for: AbbVie, V. Garg Shareholder of: AbbVie, Employee of: AbbVie, M. Yang Employee of: Analysis Group, Inc., which has received consultancy fees from AbbVie, E. Wu Employee of: Analysis Group, Inc., which has received consultancy fees from AbbVie, M. Skup Shareholder of: AbbVie, Employee of: AbbVie

DOI: 10.1136/annrheumdis-2018-eular.4975

\section{AB1277 1 VACCINATION STATUS AND KNOWLEDGE AND ATTITUDE ON VACCINE AMONG PATIENTS WITH RHEUMATIC DISEASE IN CHINA}

\author{
Y. Jiang ${ }^{1}$, X. Li ${ }^{2}$, X. Zhang ${ }^{1}$, Q. Lv¹, Y. Zhang ${ }^{1}$, J. Qi ${ }^{1}$, Z. Liao ${ }^{1}$, J. Gu ${ }^{1}$. \\ ${ }^{1}$ Rheumatology, The Third Affiliated Hospital of Sun Yat-Sen University, \\ Guangzhou; ${ }^{2}$ Rheumatology, The People's Hospital of Liuzhou City, Liuzhou, \\ China
}

Background: Rheumatic diseases are associated with an increased susceptibility to infections. ${ }^{1}$ Specific inactivated vaccinations are recommended for patients with autoimmune diseases. ${ }^{2-4}$ However, vaccination coverage among patients with rheumatic disease is extremely low in China.

Objectives: Our study was to discover infection and vaccination status in patients with rheumatic diseases in recent five years. and then to determine knowledge and attitude on vaccine among patients with rheumatic diseases.

Methods: A questionnaire-based survey was conducted in a total of 242 patients The Statistical Package for Social Sciences (SPSS) software version 21 was used for all data management and analysis.

Results: Of 242 patients, mean age was $39.84 \pm 4.42$. Mean disease duration was $30.00 \% \pm 4.42 .55 \%$ had connective tissue disease. 7 patients had herpes zoste infection. 4 had influenza. 5 had pneumonia, 1 had dengue fever. And 1 had herpes genitalis infection in recent 5 years.

Only 15 patients $(6.2 \%)$ had vaccination in recent 5 years. 2 female patients had inoculation of human papillomavirus (HPV) vaccine. 3 patients took shots of hepatitis $B$ virus (HBV). 2 were vaccinated for tetanus, 4 for rabies vaccine and 1 for influenza.

$159(65.7 \%)$ of the patients had heard of influenza vaccine. Only $62(25.6 \%)$ had heard of pneumococcal vaccine. $103(43.6 \%)$ of the participants knew where to take vaccine. Only 9 patients had reported of former doctors' advice to taking vaccine (influenza, 2). 144 (59.5\%) believed influenza could turn to serious infection.
$47.5 \%$ had correct knowledge of vaccination function. Only $42.1 \%$ believed vaccine was safe and valid. $8.3 \%$ of the patients thought vaccination was useless. $57.4 \%$ of the patients would like to take vaccine if medical insurance could cove vaccination. Only $37.6 \%$ of the patients preferred to take vaccine with doctors recommendation.

Conclusions: There is a need for educational intervention and awareness campaigns over the importance of vaccination in patients with rheumatic diseases.

\section{REFERENCES:}

[1] 1. van Assen S, Elkayam O, Agmon-Levin N, et al. Vaccination in adult patients with auto-immune inflammatory rheumatic diseases: a systematic literature review for the European League Against rheumatism evidencebased recommendations for vaccination in adult patients with auto-immune inflammatory rheumatic diseases. Autoimmun Rev 2011;10(6): 341e52.

[2] Papadopoulou D, Sipsas NV. Comparison of national clinical practice guidelines and recommendations on vaccination of adult patients with autoimmune rheumatic diseases. Rheumatol Int 2014;34(2):151e63.

[3] van Assen S, Agmon-Levin N, Elkayam O, et al. EULAR recommendations for vaccination in adult patients with autoimmune inflammatory rheumatic diseases. Ann Rheum Dis 2011;70(3):414e22.

[4] Singh JA, Furst DE, Bharat A, et al. 2012 update of the 2008 American College of Rheumatology recommendations for the use of disease-modifying antirheumatic drugs and biologic agents in the treatment of rheumatoid arthritis. Arthritis Care Res (Hoboken) 2012;64(5):625e39.

Acknowledgements: None.

Disclosure of Interest: Y. Jiang: None declared, X. Li: None declared, X. Zhang None declared, Q. Lv: None declared, Y. Zhang: None declared, J. Qi: None declared, Z. Liao Grant/research support from: National Natural Sciences Foundation of China [grant number 81201372], J. Gu Grant/research support from: the 5010 Subject of Sun Yat-sen University (2007023)

DOI: 10.1136/annrheumdis-2018-eular.2772

\section{AB1278 MOBILE DEVICE-AIDED HEALTH CARE: ADMINISTRATION OF NEW HEALTH CARE IN CHINA}

Q. Lv, Y. Jiang, J. Qi, Y. Zhang, X. Zhang, Z. Liao, Z. Lin, J. Gu. Rheumatology The Third Affiliated Hospital of Sun Yat-Sen University, Guangzhou, China

Background: , ${ }^{\text {Till }} 2016$ the total population of mainland China has reached 1.38 billion, while there are only 2.21 licensed/assistant physicians per thousand people. ${ }^{1}$ Another serious problem is uneven geographical distribution of medical resources. Less than $3 \%$ of general hospitals are responsible for more than $40 \%$ of medical service. Limited medical resources and distribution imbalance lead to countless of trans-provincial medical behaviours, resulting in an increase of economic cost and time cost. Meanwhile, China's mobile Internet communication is booming. By the end of 2016, there were 1.32 billion mobile phone users nationwide. $^{2}$ Based on these advantages, a new type of digital medical care has been developed rapidly in China.

Objectives: Our aim was to describe current situation of medical care and mobile medical care in China, and then to analyse medical big data to help manage chronic diseases such as rheumatic diseases.

Methods: Distribution and number of medical resources were acquired by the website of National Bureau of Statistics of the People's Republic of China and National Health and Family Planning Commission of the People's Republic of China. 7 biggest digital medical services and other healthcare websites or applications were compared in the aspects of application function, numbers and distribution of registered doctors and patients, and chronic disease management.

Results: According to different stages of medical interventions, operation modes of digital medical services can be divided into different types. Major functions encompass reservation, payment and medical consultancy. 3\% of applications involve the management of chronic diseases. Many mobile medical platforms rely on doctors from comprehensive hospitals. Patients with definitive diagnosis and initial treatment could be managed and followed-up via the platform. This Internet management mode of chronic diseases currently attracts 389407 specialists from comprehensive hospitals and 895921 patients with chronic diseases. Although the number of registered doctors in the southeastern areas is absolutely higher, many doctors are more accepting Internet-based medical practice in relatively poor western regions. The proportion of physicians and patient with chronic diseases is very large. The top 5 departments of registered users are related to chronic diseases.

Conclusions: Limited medical and health resources and distribution imbalance is a serious problem in China. A new mode of digital medical service may help manage chronic diseases. 